\title{
COVID-19: The Strategy of Medicine and the Anatomy of Fear
}

\author{
Igor Klepikov* \\ *MD, professor, retired. USA \\ *Corresponding Author: Igor Klepikov MD, professor, retired. USA
}

\section{Mini ReVIEW}

The existence of the coronavirus has been known for several decades, and medicine has already faced its epidemics (1), but the current pandemic has become an unpleasant surprise not so much for the inhabitants of the planet as for medical workers. What happened and how did the best healthcare systems fail to provide real care to their patients? Why is the medical staff working on the front line forced to actually passively observe the dynamics of the disease, not being able to really slow down its development (2-6)? Is the coronavirus really so dangerous and terrible, despite the fact that the vast majority of infected people endure a "meeting" with this "monster" without consequences and without treatment? What was the reason for the unexpected catastrophe that changed the life of the entire planet, in the simple and sudden increase in aggressiveness of one of the representatives of the microcosm, or in this case there were other prerequisites for this catastrophe, the signs of the approach of which were not timely noticed and evaluated?

If you look for answers to such questions from the point of view of fundamental medical science, they literally lie on the surface, but the view of the main problem of COVID-19, lung damage, is based on the former narrowly focused concept of acute pneumonia (AP), which initially shifts the emphasis in the study of this topic. Many experts consider this event a natural disaster, not giving serious importance to the steady growth of viruses among the pathogens of AP in recent years and the lack of any practical adjustments in the strategy of this direction. Today, the word "coronavirus" is associated with the constant danger of infection and disease and creates an additional verbal halo of fear. At the same time, no one pays attention to the fact that the pathogen itself is not the direct cause of critical conditions and deaths. Moreover, in a huge number of infected people, it does not show any signs of its presence at all, isn't it?
Currently, COVID-19 is presented by the media and is perceived in society almost as a "plague of the 21 st century", but the observation materials accumulated during the pandemic do not provide unambiguous grounds for such an assessment, but on the contrary allow us to note the reasons for the exaggerated demonization of the coronavirus. A huge mass of infected people around the world falls into the statistical groups of the pandemic only due to specific testing, while mild clinical signs of infection do not even always come to the attention of doctors. The whole essence of the problem is fully manifested in patients with coronavirus pneumonia. It is the defeat of the lung tissue that today marks the uncertainty of the prognosis and the lack of any guarantees of effective medical care.

Clinical symptoms of lung damage in coronavirus infection in combination with the results of laboratory, radiological and pathoanatomical studies reflect a typical picture of AP, although they differ in some nuances (711). At the same time, the peculiarities of the course of the pandemic show that the spread of a single pathogen with an infinite range of individual manifestations, including asymptomatic infection, is evidence that the microbiology of AP is one of the triggering factors, but not the main and only cause of the disease. The division of patients according to the severity of infection occurs spontaneously. In this process, medicine is just an observer, because it has no leverage over existing trends, right?

As long as the manifestations of coronavirus infection do not pose a threat to life and the patient does not need hospitalization, the situation looks quite safe and calm. However, the most severe cases of COVID-19 are concentrated in hospitals, where there is an additional separation of patients for treatment in emergency departments. It is the hospitalized patients who are in urgent need of effective medical care, and it is in this situation that the 
impotence of modern medicine before the emerging and progressive disease is clearly manifested. In my opinion, the term "powerlessness" best describes a situation that is ubiquitous and that is the main cause of fear, depression and the introduction of strict quarantine measures. The numerous and constantly published reports on the results of treatment of this group of patients today do not depend on countries, the level of development of their health systems and the degree of training of doctors. Statistical differences are insignificant, but trends in indicators are stable.

Currently, a patient with COVID-19 can only rely on oxygen support during hospitalization with subsequent transfer to auxiliary ventilation (12-17). Various reports on the pharmacology of treatment contain attempts to provide such assistance, but in the end note the lack of effect $(5,8,18-23)$. The latest discussions relate to several drugs and areas of care that have been tested repeatedly and unsuccessfully during this short period of time. Prospects for providing medical care to such patients are persistently considered in the light of neutralization of the pathogen. Statements about the need for a new strategy are based on the preservation of the previous ideology and offer tactical amendments and options $(7,16,22,24,25,42-44)$.

Overall mortality among hospitalized patients with COVID-19 today reaches $11-20 \%$ (26-28), and in intensive care units - 30-50\% (29-32). Many people today associate successful care in critical situations with the possibility of timely provision of patients with auxiliary ventilation. However, the mortality rate among patients connected to ventilators is the highest, exceeding $50 \%(28,31,32)$, which gives reason to draw the opposite conclusion.

But the most unexpected surprise for many may be the comparison of these indicators with the death rate in community-acquired pneumonia, which was recorded in recent years. The rate of deaths in bacterial forms of AP in intensive care units was the same 30-50\% (33-37). If we draw Parallels between AP on the eve of the pandemic and now, when it comes to viral inflammation in the lungs, we can note that in recent years, despite the availability of reasonable treatment, the same natural selection has occurred as now in the group of the most severe patients. The only difference is that earlier failures in treatment were explained by the special virulence of the microflora and the shortcomings of antibacterial therapy, and now all patients, in relation to the pathogen of the process, are on an equal footing.

Many experts were convinced that patients with AP received evidence-based and adequate treatment even before the outbreak of the pandemic. However, in this regard, it is worth remembering that recently the annual number of cases of AP in the world was up to 450 million cases, and the number of deaths reached 4 million (38.39). These figures, little known even to doctors, are an order of magnitude higher than the statistics of the current pandemic, but no one in the world has sounded the alarm at least close to today about this situation. It should be noted that the total figure in these reports reflects the number of cases, and not infected, as it is now. Maybe in those years there was a discussion about the need for a strategic review in solving this problem? On the contrary, the principle of suppressing the pathogen of AP remained the leading one in the treatment of such patients before the outbreak of the pandemic, and antibiotics continued to be considered as the "cornerstone" among treatment methods (40.41).

Today, based on the previously studied concept of the disease, numerous attempts are being made to find ways to neutralize the pathogen. The discussed directions suggest achieving this goal by studying the mechanisms of action at the cellular, molecular, and even genetic level, leaving aside such important details of the dynamics of pathological processes as causation $(7,21,23,42-44)$. It is well known that when determining the diagnosis and assessing the severity of incoming patients with AP, doctors first of all want to know the results of x-ray examination of the lungs, reflecting the degree of inflammatory damage, pushing the etiology of the process to the background, is not it? However, after the diagnosis of AP, attention is again switched to its etiology, as the main goal of therapeutic efforts, although at this stage of the disease, the type of pathogen is no longer important for the patient's body, since he suffers from a violation of the functions of the organ affected by inflammation.

Further progression of the disease leads to a violation of peripheral hemodynamics, the causes of which are due to changes in blood flow in the small circle of blood circulation and a violation of coordination between the two halves of the cardiovascular system. However, this clinical picture continues to be explained only by the action of the pathogen and the 
development of viral shock (45). Objective evidence of this nature of shock is not presented by anyone, but this point of view prevails. Applying, according to this concept, General therapeutic methods of assistance, you can get the opposite result. Therefore, there is serious concern about the "presence of unexplained hemodynamic instability" against the background of its correction in patients with COVID-19 pneumonia (22), while the explanation is related to the localization of inflammation.

The assessment of the causes of the severity of the condition of patients with AP and how to help in such situations completely depend on our understanding of the nature and pathogenesis of the disease. Forty years ago, no one questioned the leading role of antibiotics in the treatment of inflammatory processesyet. However, the harsh local conditions with the concentration of superaggressive forms of AP forced to reconsider the concept of this problem even then. The work done made it possible not only to achieve excellent results and the possibility of guaranteed prevention of complications, but also to show the secondary role of etiotropic methods of treatment in the overall complex of medical care (46).

Today's observations of coronavirus pneumonia with an increase in the number of hospitalizations, rapid development of the disease and high mortality actually repeat the conditions in which the above work was performed. The development of this situation looks and is perceived by many as a sudden catastrophe. However, an analysis of the state of medical care for patients with AP on the eve of the pandemic indicates its questionable effectiveness and the presence of a number of facts and contradictions mentioned above, which indicate the need for a radical revision of views on the nature and solution of this problem. A sharp change in the etiological factors of the disease and the loss of hope for conventional etiotropic therapy only focused attention on issues that are long overdue and need to be addressed.

Statistics allow any of us to make sure that the number of people infected with coronavirus in the year of the current pandemic is significantly lower than the number of people infected with AP in the same period, as well as the number of deaths. The experience of anti-epidemic measures, including total re-quarantines at the country level, does not stop the spread of this infection, although, as is already known, the very fact of infection for many people is not dangerous. Anxiety is caused by the inability to accurately predict events in the event of infection, and the real problem is the development of viral pneumonia with a progressive course, since medicine does not have a specific treatment for this disease.

If today there were effective ways to help with AP, then hospital medicine would retain a sufficient halo of reliability, and it is unlikely that such strict restrictive measures would be required. In order to really correct this situation, modern medicine has a huge array of scientific materials on this problem, which allow us to understand the shortcomings of the existing concept of AP and clarify the mechanisms of its development. The logical consequence of the new perception of the problem will be a new strategy with access to pathogenetically based specific treatment methods. Excessive attention to the causative agents of AP has grown in the light of current events into an urgent need for a change of strategy, and unsuccessful attempts to change the situation directly and clearly indicate that it is time to move from words to deeds.

\section{BIBLIOGRAPHY}

[1] https://en.wikipedia.org/wiki/Severe_acute_res piratory_syndrome

[2] Lai J, Ma S, Wang Y, et al.(2020). Factors associated with mental health outcomes among health care workers exposed to coronavirus disease 2019. JAMA Netw Open 2020;3(3):e2 03976-e203976.

[3] R. E. Leiter (2020). Reentry. NEJM, October 14, 2020. DOI: 10.1056/NEJMp2027447

[4] J. N. Rosenquist (2020). The Stress of Bayesian Medicine - Uncomfortable Uncertainty in the Face of Covid-19.NEJM, October 7, 2020. DOI: 10.1056/NEJMp2018857

[5] $\mathrm{Xu}$ Chen. "Avoiding Defensive Medicine among Pandemic". EC Emergency Medicine and Critical Care 4.12 (2020): 49-53.

[6] I. Zagury-Orly, R. M. Schwartzstein, (2020). Covid-19 - A Reminder to Reason. N Engl J Med 2020; 383:e12, DOI: 10.1056/NEJMp20 09405

[7] Lipman M, Chambers RC, Singer M, et al. (2020). SARS-CoV-2 pandemic: clinical picture of COVID-19 and implications for research. Thorax 2020;75:614-616.

[8] J. H. Stone, M. J. Frigault, N. J. Serling-Boyd et al. (2020). Efficacy of Tocilizumab in Patients Hospitalized with Covid-19. NEJM, October 21, 2020, DOI: 10.1056/ NEJMoa 202 8836 
[9] M. Ackermann, S. E. Verleden, M. Kuehnel at al. (2020). Pulmonary Vascular Endothelialitis, Thrombosis, and Angiogenesis in Covid-19. May 21, 2020. DOI: 10.1056/NEJMoa2015432

[10] Martines RB, Ritter JM, Matkovic E et al; COVID-19 Pathology Working Group (2020). Pathology and Pathogenesis of SARS-CoV-2 Associated with Fatal Coronavirus Disease, United States. Emerg Infect Dis. 2020 Sep; 26 (9):2005-2015. doi: 10.3201/eid2609.202095. Epub 2020 May 21. PMID: 32437316; PMCID: PMC7454055.

[11] C.N.Englisch, T.Tschernig,F,Flockerzi et al. (2020). Lesions in the lungs of fatal corona virus disease Covid-19. Annals of Anatomy Anatomischer Anzeiger, 2020. https://doi.org/ 10.1016/j.aanat.2020.151657

[12] Koeckerling D, Barker J, Mudalige NL, et al. (2020). Awake prone positioning in COVID19. Thorax Published Online First: 16 June 2020. doi: 10.1136/thoraxjnl-2020-215133

[13] Thompson AE et al. (2020) Prone positioning in awake, nonintubated patients with COVID19 hypoxemic respiratory failure. JAMA Intern Med 2020 Jun 17; [e-pub]. (https://doi.org/10. 1001/jamainternmed.2020.3030)

[14] Winearls S, Swingwood EL, Hardaker CL, et al. (2020). Early conscious prone positioning in patients with COVID-19 receiving continuous positive airway pressure: a retrospective analysis. BMJ, Open Respiratory Research, 2020;7:e000711. doi: 10.1136/bmjresp-2020-00 0711

[15] Vianello A, Arcaro G, Molena B, et al. (2020). High-flow nasal cannula oxygen therapy to treat patients with hypoxemic acute respiratory failure consequent to SARS-CoV-2 infection. Thorax. Published Online First: 23 July 2020. doi: 10.1136/thoraxjnl-2020-214993

[16] D. A. Berlin, R. M. Gulick, F. J. Martinez (2020). Severe Covid-19. NEJM, May 15, 2020, DOI: 10.1056/NEJMcp2009575

[17] M. L. Ranney, V. Griffeth, A. K. Jha (2020). Critical Supply Shortages — The Need for Ventilators and Personal Protective Equipment during the Covid-19 Pandemic. NEJM, 2020; 382:e41 DOI: 10.1056/NEJMp2006141

[18] V. A. Simonovich, L. D. Burgos Pratx, P. Scibona et al. (2020). A Randomized Trial of Convalescent Plasma in Covid-19 Severe Pneumonia. November 24, 2020. DOI: 10.105 6 /NEJMoa2031304

[19] O. Mitjà, M. Corbacho-Monné, M. Ubals et al. (2020). A Cluster-Randomized Trial of Hydroxychloroquine for Prevention of Covid19. November 24, 2020. DOI: 10.1056/ NEJM oa2021801

[20] WHO Solidarity Trial Consortium (2020). Repurposed Antiviral Drugs for Covid-19 Interim WHO Solidarity Trial Results.
December 2, 2020. DOI: 10.1056/ NEJM oa2 023184

[21] E. Huang, S. C. Jordan (2020). Tocilizumab for Covid-19 - The Ongoing Search for Effective Therapies. December 10, 2020. N Engl J Med 2020; 383:2387-2388. DOI: 10.1056/NEJMe 2032071

[22] D. A. Berlin, R. M. Gulick, F. J. Martinez (2020). Severe Covid-19. December 17, 2020. N Engl J Med 2020; 383:2451-2460. DOI: 10.1056/NEJMcp2009575

[23] Rwik Sen (2020). High-throughput approaches of diagnosis and therapies for COVID-19: antibody panels, proteomics and metabolomics. Future Drug Discovery 2020;.Published Online:3 Dec 2020https://doi.org/10.4155/fdd2020-0027

[24] Amr Abdel-MordyKandeel (2020). Do We Need Changes in Management Strategies of COVID-19 Pandemic? Vitamin D as a Balance Key for Health-Economy Dilemma. http://dx. doi.org/10.5281/zenodo.3782752, Iberoam J Med, vol.2, n4, p.250-252, 2020

[25] V. E. Schaye, J. A. Reich, B. P. Bosworth et al. (2020). Collaborating Across Private, Public, Community, and Federal Hospital Systems: Lessons Learned from the Covid-19 Pandemic Response in NYC. NEJM Catalyst Innovations in Care Delivery 2020; 06, Vol. 1 No. 6, November - December 2020. DOI:https:// doi. org/10.1056/CAT.20.0343

[26] P-Y. Boëlle, T. Delory, X. Maynadier et al, (2020). Trajectories of Hospitalization in COVID-19 Patients: An Observational Study in France. J. Clin. Med.2020,9, 3148; doi:10.3390 /jcm9103148www.mdpi.com/journal/jcm

[27] C. Salama, J. Han, L. Yau et al. (2020). Tocilizumab in Patients Hospitalized with Covid-19 Pneumonia. December 17, 2020. DOI: 10.1056/NEJMoa2030340

[28] Karagiannidis C, Mostert C, Hentschker C, et al. Case characteristics, resource use, and outcomes of 10021 patients with COVID-19 admitted to 920 German hospitals: an observational study. Lancet Respir Med 2020; 8:853-862.

[29] Renato Seligman and Beatriz Graeff Santos Seligman (2020). "Pandemic in the 21st Century. The Challenge of COVID-19”. EC Pulmonology and Respiratory Medicine 9.8 (2020): 30-31.

[30] Grasselli G et al. (2020). Baseline characteristics and outcomes of 1591 patients infected with SARS-CoV-2 admitted to ICUs of the Lombardy region, Italy. JAMA $2020 \mathrm{Apr}$ 6; [e-pub]. (https://doi.org/10.1001/ jama. 2020. 5394)

[31] S. Richardson, J. S. Hirsch, M. Narasimhan at al. (2020). Presenting Characteristics, 
Comorbidities, and Outcomes Among 5700 Patients Hospitalized With COVID-19 in the New York City Area. JAMA. Published online April 22, 2020. doi:10.1001/jama.2020.6775

[32] Gupta S, Wang W, Hayek SS, et al. Association between early treatment with tocilizumab and mortality among critically ill patients with COVID-19. JAMA Intern Med. 2020; 180 (11) :1436-1446.doi:10.1001/jamainternmed.2020.3 596

[33] A. Liapikou,E. Rosales-Mayor,A.Torres (2014). The management of severe community acquired pneumonia in the ICU.June 2014, Expert Review of Respiratory Medicine 8(3) :293-303.DOI: 10.1586/17476348.2014.896202

[34] J. W. Kim, , J.J. Kim, H. J. Yang at al.(2015). The Prognostic Factors of Pneumonia with Septic Shock in Patients Presenting to the Emergency Department. Korean Journal of Critical Care Medicine 2015; 30(4): 258-264

[35] P. Jason,N. C. Dean, Q. Guo et al. (2016). Severe community-acquired pneumonia: timely management measures in the first 24 hours. Critical Care, 2016,20:237

[36] A. Vidal, L. Santos (2017). Comorbidities impact on the prognosis of severe acute community-acquired pneumonia.Porto Biomedical Journal, Vol. 2. Num. 6.November - December 2017, pages 247-346

[37] A.Ceccato, A. Torres (2018). Sepsis and community-acquired pneumonia. Ann Res Hosp 2018;2:7

[38] Rudan I, Boschi-Pinto C, Biloglav Z, Mulholland K, Campbell H. Epidemiology and etiology of childhood pneumonia. Bull World Health Organ. 2008;86:408-416. [PMC free article] [PubMed] [Google Scholar]

[39] WHO Revised global burden of disease 2002 estimates. 2004. http://www.who.int/ health info/global_burden_disease/estimates_regional _2002_revised/en/ (accessed Nov 5, 2010).
[40] Paula Peyrani, Lionel Mandell, Antoni Torres \& Glenn S Tillotson (2019) The burden of community-acquired bacterial pneumonia in the era of antibiotic resistance, Expert Review of Respiratory Medicine, 13:2, 139-152, DOI: 10.1080/17476348.2019.1562339

[41] J. P. Metlay, G. W. Waterer, A. C. Long at al.; on behalf of the American Thoracic Society and Infectious Diseases Society of America. "Diagnosis and Treatment of Adults with Community-acquired Pneumonia. An Official Clinical Practice Guideline of the American Thoracic Society and Infectious Diseases Society of America". American Journal of Respiratory and Critical Care Medicine, Volume 200, Issue 7, 1 October 2019, Pages e45-e67, https://www.atsjournals. org/doi/full/ 10.1164/rccm.201908-1581ST

[42] Mo Shehata. "Covid-19; The Possible Medical Strategies". EC Pulmonology and Respiratory Medicine 9.6 (2020): 03-07.

[43] V. J. Dzau,C.Balatbat (2020). Strategy, coordinated implementation, and sustainable financing needed for COVID-19 innovations. The Lancet Journal, Nov 07, 2020, Volume 396, Number 10261p1463-1534, e73-e82. DOI: https://doi.org/10.1016/S0140-6736(20)32289-3

[44] El-Shimy, IA, Mohamed, MM, Hasan, SS, Hadi, MA. Targeting host cell proteases as a potential treatment strategy to limit the spread of SARS-CoV-2 in the respiratory tract. Pharmacol Res Perspect. 2021; 9:e00698. https://doi.org/10.1002/prp2.698

[45] Alhazzani W et al. Surviving sepsis campaign: Guidelines on the management of critically ill adults with coronavirus disease 2019 (COVID19).Crit Care Med 2020 Mar 27; [e-pub]. (https://doi.org/10.1097/CCM.00000000000043 63)

[46] Igor Klepikov (2020). "Acute pneumonia. New doctrine and first treatment results." LAPLambert Academic Publishing. 2020. ISBN10:6202679174; ISBN-13: 9786202679176

Citation: Igor Klepikov, "COVID-19: The Strategy of Medicine and the Anatomy of Fear”, International Journal of Research Studies in Medical and Health Sciences. 2021; 6(1): 16-20. DOI: https://doi.org/ 10.22259/ijrsmhs.0601003

Copyright: (C) 2021 Igor Klepikov, This is an open-access article distributed under the terms of the Creative Commons Attribution License, which permits unrestricted use, distribution, and reproduction in any medium, provided the original author and source are credited. 